\title{
Estudo da biomecânica oclusal e da aderência da resina acrílica auto-polimerizável (polimetilmetacrilato) em fraturas de rinoteca de tucanos (Ramphastos toco) ${ }^{1}$
}

\author{
Roberto Silveira Fecchio ${ }^{2}$, Marcelo Silva Gomes ${ }^{3}$, Jorge Kolososki ${ }^{4}$, Bruno \\ Simões Sergio Petri ${ }^{5}$, João Luiz Rossi Jr² e Marco Antonio Gioso ${ }^{2,6}$
}

\begin{abstract}
Fecchio R.S., Gomes M.S., Kolososki J., Petri B.S.S., Rossi Jr J.L. \& Gioso M.A. 2008. [Study of the occlusion biomechanics and adherence of acrylic resin (polimetilmetacrilate) in fractures of rhinotheca in toucans (Ramphastos toco).] Estudo da biomecânica oclusal e da aderência da resina acrílica auto-polimerizável (polimetilmetacrilato) em fraturas de rinoteca de tucanos (Ramphastos toco). Pesquisa Veterinária Brasileira 28(7):335-340. Departamento de Cirurgia, Faculdade de Medicina Veterinária e Zootecnia, Universidade de São Paulo, Prof. Dr. Orlando de Marques de Paiva 87, Bloco 8 superior, Cidade Universitária, São Paulo, SP 05508-270, Brazil. Email: rfecchio@gmail.com

Traction effort was applied perpendicularly to the axis of toucan beaks and for accomplishment of the essay a dynamometer was used. The beak was completely fractured when submitted to traction of $270.40 \mathrm{~N}$. For fixation of the fractured beaks acrylic resin was applied using a strip of $2.0 \mathrm{~cm}$ of width. The second beak presented resistance up to 69.75 $\mathrm{N}$. The third beak was submitted to acid conditioning and resisted to force of $63.29 \mathrm{~N}$. Other two new tests were accomplished the whole surface of the rhinotheca filled out. The fourth beak was not submitted to the acid attack and it resisted up to $134.40 \mathrm{~N}$, and the fifth was submitted to the acid etch and it resisted up to $101.50 \mathrm{~N}$. The present work did not observe statistical correlation and, consequently, differences among the procedures with previous use of acid attack and those without the use of the same.
\end{abstract}

INDEX TERMS: Toucans, rhinotheca, fracture, acid conditioning, beak.

RESUMO.- Esforço de tração foi aplicado perpendicularmente ao eixo do bico e para realização do ensaio foi utilizado um dinamômetro. O bico íntegro fraturou quando submetido

\footnotetext{
${ }^{1}$ Recebido em 17 abril de 2008.

Aceito para publicação em 11 de junho de 2008.

2 Laboratório de Odontologia Comparada (LOC), Faculdade de Medicina Veterinária e Zootecnia (FMVZ), Universidade de São Paulo (USP). Av. Prof. Dr. Orlando de Marques de Paiva 87, Bloco 8-superior, Cidade Universitária, São Paulo, SP 05508-270, Brasil.

${ }^{3}$ Médico Veterinário do Zoológico Municipal de São Bernardo do Campo, Parque Estoril, Rua Portugal s/n, Bairro Estoril, Riacho Grande, São Bernardo do Campo, SP 09831-000, Brasil.

${ }^{4}$ Departamento de Engenharia Metalúrgica e de Materiais, Fundação Educacional Inaciana (FEI), Av. Humberto de Alencar Castelo Branco 3972, São Bernardo do Campo, SP 09850-901.

${ }^{5}$ Médico Veterinário do Parque Ecológico do Tietê, Rua Guira Acangatara 70, Engenheiro Goulart (Zona Leste), São Paulo, SP 03719-000.

6 Departamento de Cirurgia, FMVZ-USP, Av. Prof. Dr. Orlando de Marques de Paiva 87, Bloco 8 superior, Cidade Universitária, São Paulo, SP 05508-270. *Autor para correspondência: rfecchio@gmail.com
}

a uma tração de $270,40 \mathrm{~N}$, com deslocamento de 22,59mm. Para a fixação dos bicos fraturados foi utilizada resina acrílica e a área compreendeu uma faixa com $2,0 \mathrm{~cm}$ de largura. $\mathrm{O}$ segundo bico ensaiado apresentou resistência até $69.75 \mathrm{~N}$. O bico submetido a condicionamento ácido resistiu a uma força de $63,29 \mathrm{~N}$. Outros dois novos ensaios foram realizados, preenchendo-se toda a superfície da rinoteca. Aquele não submetido ao condicionamento ácido resistiu até 134,40 $\mathrm{N}$ e, aquele submetido ao condicionamento ácido, resistiu até $101,50 \mathrm{~N}$. No presente trabalho não se observou correlação estatística e, conseqüentemente, diferença entre os procedimentos com utilização prévia de condicionamento ácido e aqueles sem a utilização do mesmo.

TERMOS DE INDEXAÇÃO: Tucano, rinoteca, condicionamento ácido, bico.

\section{INTRODUÇÃO}

Materiais biológicos são combinações complexas, hierarquicamente estruturados e multifuncionais. As proprieda- 
des mecânicas destes materiais são excelentes, considerando os frágeis componentes dos quais são constituídos. A arquitetura anatômica dos materiais biológicos é frequentemente composta por minerais e estruturas orgânicas que, isoladamente, não conferem rigidez, porém quando organizados proporcionam incríveis graus de resistência. Estas estruturas complexas decorrentes de milhões de anos de evolução são inspiradoras no desígnio de materiais sintéticos modernos (Meyers et al. 2006).

O bico das aves é uma estrutura dinâmica em crescimento constante, constituída pelos ossos maxilares superior (pré-maxila e nasal) e inferior (mandíbula), cobertos por bainhas epidérmicas queratinizadas, denominado de ranfoteca (Ritchie et al. 1994, Rupley 1999) (Fig.1). Outras estruturas também compõem o bico como feixes vásculonervosos, articulações e bainhas germinativas (Rossi et al. 2005). Anatomicamente a ranfoteca é subdividida em rinoteca (superior) e gnatoteca (inferior) (Rupley 1999). A mucosa da cavidade oral e da língua das aves é recoberta por epitélio escamoso estratificado e o grau de queratinização varia de acordo com a localização do epitélio na cavidade oral (Rossi et al. 2005) e da espécie animal.

Os bicos das aves são, normalmente, curtos e gros-

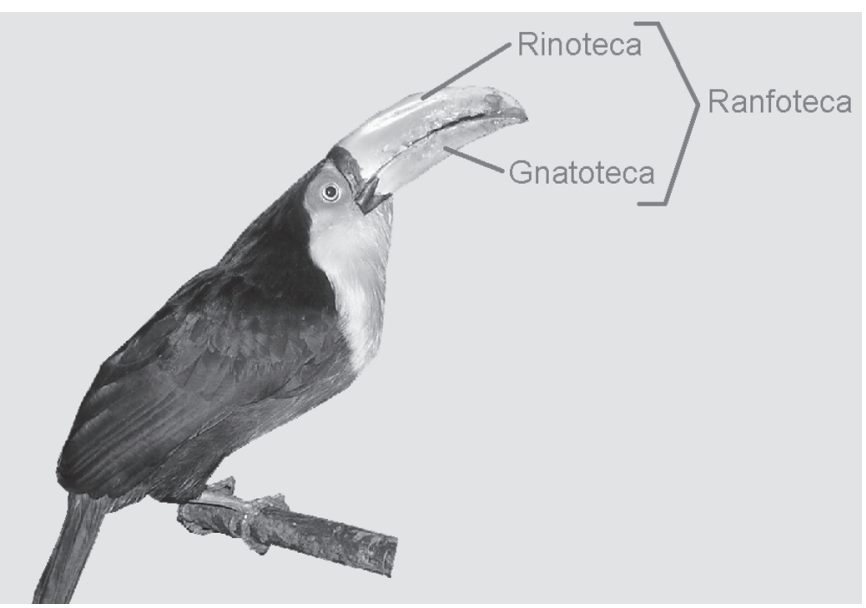

Fig.1. Ilustração da ranfoteca e suas subdivisões (rinoteca e gnatoteca) em tucano-de-bico-verde (Ramphastos dicolorus).

sos ou longos e finos. O bico de tucano é uma exceção: é longo e grosso. Seu comprimento abrange cerca de um terço do comprimento total do animal, porém seu peso representa aproximadamente $1 / 20$ ou $5 \%$ do peso vivo total do animal. Sua densidade é de aproximadamente $0.1 \mathrm{~g} / \mathrm{cm}^{3}$, o que permite ao tucano voar mantendo o centro de massa no plano das asas (Meyers et al 2006). Apesar disso, o bico do tucano apresenta resistência biomecânica extraordinária. Basicamente a estrutura do bico de tucanos é um sanduíche composto por queratina e uma rede fibrosa trabeculada de osso e proteínas ricas em cálcio (Meyers et al. 2006). A espessura da camada de queratina varia entre 0,5 e $0,75 \mathrm{~mm}$ e está arranjada na forma de sobreposições de placas hexagonais.
A consistência da ranfoteca varia entre as espécies, sendo firme em Psitaciformes (papagaios, periquitos e araras) e macia e flexível em Anseriformes (gansos) (Ritchie et al. 1994). A ranfoteca pode ser considerada como estrato córneo do bico e a derme é bem vascularizada e conectada ao periósteo. Fatores causais como trauma e necrose da derme podem freqüentemente resultar em lesões que induzem deformidades no bico (Ritchie et al. 1994).

A ranfoteca possui variadas funções em diferentes espécies de aves, como preensão de alimento, preparo do mesmo para a deglutição, defesa e ataque, interação social e sexual, locomoção bem como construção de ninhos (Ritchie et al. 1994, Rupley 1999, Rossi et al. 2005). O crescimento da queratina do bico ocorre sempre que houver uma camada germinativa subjacente (aderida ao periósteo), mas as linhas de crescimento inclinam-se no sentido da ponta do bico (Getty 1989). O tempo de reposição de queratina da ranfoteca está intimamente ligado ao uso do bico. Em grandes psitacídeos a substituição completa da ranfoteca ocorre em aproximadamente seis meses, enquanto que nos ranfastídeos há uma taxa de crescimento aproximada de $0,5 \mathrm{~cm}$ num período de dois anos (Ritchie et al. 1994). Normalmente a queratina da gnatoteca é substituída de duas a três vezes mais rápido do que a rinoteca (Ritchie et al. 1994).

Diversas porções do aparelho digestivo das aves, incluindo o bico, são modificações adaptativas em função da dieta. O tamanho do bico é um importante fator na regulação do alimento ingerido, mostrando que as aves possuem grandes dificuldades em consumir itens alimentares maiores ou menores do que a dimensão anatômica do bico, havendo uma relação direta entre a anatomia do bico e a preferência alimentar de cada espécie (Rossi et al. 2005).

A variação de defeitos congênitos e adquiridos pode interferir na função normal do bico. Em galináceos (pavão, mutuns, jacutingas), a deformidade de rinoteca pode estar associada a deficiências embriogênicas de ácido fólico, biotina e ácido pantotênico.

Dentre alguns exemplos de problemas adquiridos destacam-se malformações, necrose do bico ou traumas incluindo perfurações, lacerações, rachaduras e avulsões. As fraturas traumáticas, especialmente da mandíbula ocorrem freqüentemente em psitacídeos que se autotraumatizam em objetos presentes no recinto ou como resultado de brigas (Ritchie et al. 1994, Rupley 1999). Neste último caso, observa-se que a incidência de fraturas de bico de psitacídios é maior nos meses de primavera e verão, devido ao comportamento reprodutivo dos animais pareados. Durante o cortejo, o macho tenta estimular a fêmea bicando delicadamente o seu bico. Se o macho for agressivo, a fêmea inexperiente e, associado a estes fatores, o recinto for pequeno, a fêmea não consegue esquivar-se do cortejo. O macho, na tentativa de segurar a fêmea, pode acabar imprimindo força demasiada e então, nestes casos, pode ocorrer fratura. 
Ford (1998) relata que aves de rapina em natureza têm os bicos desgastados naturalmente pelo hábito da caça e ingestão de presas (em alguns casos a ave descarna parte da presa e o atrito do bico contra os ossos provoca o desgaste). Em cativeiro o bico tende a não desgastar e necessita de auxílio para tanto.

As anormalidades do bico podem ocorrer como resultado de má nutrição, incubação inapropriada, infecção viral, bacteriana, fúngica e parasitária e traumas (Ritchie et al. 1994, Rupley 1999). Esses fatores podem gerar crescimento exagerado do bico, cruzamento de rinoteca e gnatoteca ("bico em tesoura"), encurtamento do bico superior (prognatismo), infecções, necrose e fraturas (Ritchie et al. 1994, Rossi et al. 1994, Rupley 1999).

As lesões decorrentes de traumatismos são as mais prevalentes das lesões de bico e variam de acordo com a intensidade do trauma. As fendas e fissuras são decorrentes de traumas leves e normalmente são tratadas por meio de anti-sepsia local e recobertas com resina acrílica, de forma a evitar infecções (Ritchie et al. 1994, Rossi et al. 1994, Rupley 1999). As lesões perfurantes são decorrentes de traumas específicos, por meio de materiais pontiagudos e devem ser recobertas com resina acrílica ou composta até completa reposição de queratina, que ocorre entre 2 e 3 semanas (Rupley 1999). Já as fissuras e lesões perfurantes pouco extensas podem ser recobertas com esparadrapo a base de celulose (Micropore $\AA$ ) e cola instantânea a base de cianocrilato (Super Bonder ${ }^{\circledR}$ ), porém esta última possui substâncias tóxicas e não deve ser depositada diretamente sobre o bico. Em casos de infecção bacteriana secundária, deve-se administrar antibiótico sistêmico.

As fraturas de rinoteca e gnatoteca são decorrentes de traumas intensos devido a disputas entre machos, agressões interespecíficas, agressões entre companheiros de recinto e choques mecânicos contra objetos do recinto (principalmente em animais recém introduzidos no cativeiro) (Cubas 2003).

As fraturas necessitam de fixação e estabilização, de forma a reposicionar corretamente os fragmentos (Rupley 1999, Cubas 2003, Rossi Jr et al. 2005) e promover imediato retorno do bico à sua função. Fraturas horizontais sobre o eixo nasomaxilar apresentam maior complicação no reparo, necessitando de um maior tempo de procedimento e prognóstico reservado. As fraturas completas de rinoteca são de extrema dificuldade de reparo, principalmente em tucanos, necessitando de próteses complexas e com grande número de insucessos nos tratamentos. Nos demais tipos de fratura, o tratamento está diretamente ligado à extensão da fratura e local acometido da ranfoteca, onde as fraturas próximas à face são mais complicadas em função das forças biomecânicas que sofrerão durante o pós-cirúrgico (Fecchio et al. 2005).

Diversos fatores como a anatomia particular, peso bastante reduzido do bico, além do desconhecimento da intensidade e distribuição das forças aplicadas regularmente sobre estes e da interação das resinas com a superfície de queratina, são responsáveis por um grande número de insucessos nos tratamentos (Fecchio et al. 2005).

As estruturas dos materiais biológicos são combinações complexas que estão sendo investigadas extensivamente por Biólogos, Médicos Veterinários, Engenheiros e outros cientistas com meta de reproduzi-las em sistemas sintéticos. Esta, realmente, é uma fronteira nova da ciência de materiais e um fértil fundamento inovador de trabalho.

\section{MATERIAL E MÉTODOS}

Objetivou-se, neste trabalho, correlacionar as propriedades mecânicas e estruturais do bico de tucano e os efeitos microscópicos do condicionamento ácido (ácido fosfórico 37\%) no estrato córneo queratinizado dos bicos de Tucanos (Ramphastos sp.), bem como a sua relação com a aderência de resina acrílica odontológica (polimetilmetacrilato) no mesmo estrato. Tal estudo baseou-se nos efeitos de maior aderência da resina acrílica obtidos com a utilização de condicionamento ácido em esmalte dentário de cães (Gioso et al. 1995).

Para correlacionar as propriedades mecânicas e estruturais do bico de tucano e avaliar as formas de fixação das fraturas de rinoteca, com a utilização de resina acrílica odontológica (polimetilmetacrilato), realizaram-se ensaios de flexão no Laboratório de Materiais do Centro Universitário da FEI (Fundação Educacional Inaciana). Para realização desses ensaios foram utilizadas rinotecas de tucano (Ramphastos toco) provenientes de cadáveres. Enfatiza-se que nenhum tipo de avaliação foi realizado com espécimes vivas.

Com a finalidade de simular os esforços a que o bico é submetido durante a alimentação, optou-se pela realização de ensaios de flexão sobre o eixo das forças oclusais (perpendicular ao eixo rostro-caudal do bico). Para tanto, foram utilizados cinco bicos, dos quais o bico número 1 estava íntegro e serviu como referência. A extremidade caudal do bico foi engastada em um suporte de resina epóxi (cerca de $2 \mathrm{~cm}$ ) enquanto na rostral (cerca de $1 \mathrm{~cm}$ da extremidade) fitou-se uma presilha de náilon autotravante, que por sua vez estava conectada ao cabeçote móvel do dinamômetro por meio de um tirante de aço (Fig.2). O esforço de tração foi aplicado perpendicularmente ao eixo do bico e para realização do ensaio foi utilizado um dinamômetro EMIC, modelo

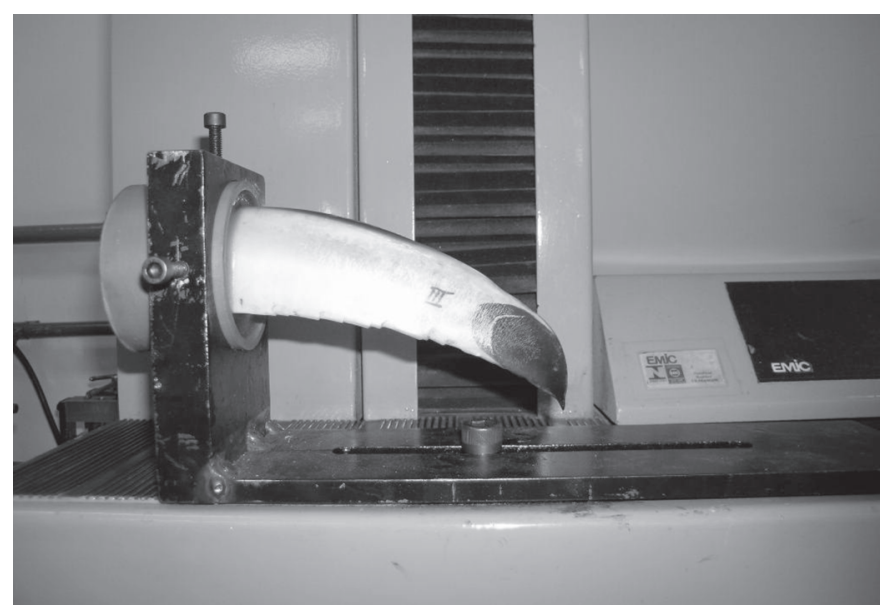

Fig.2. Fixação dos bicos de tucanos (Ramphastos toco) em dinamômetro para realização dos ensaios laboratoriais de flexão. 


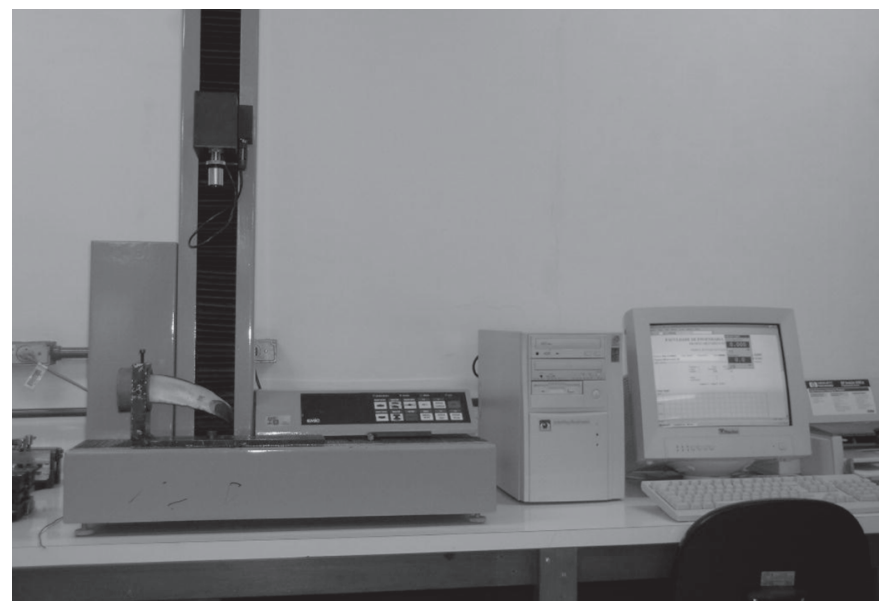

Fig.3. Esquema demonstrando a fixação do bico ao cabeçote móvel do dinamômetro, cujos dados obtidos eram transferidos ao computador ao lado por meio de programa computacional especializado.

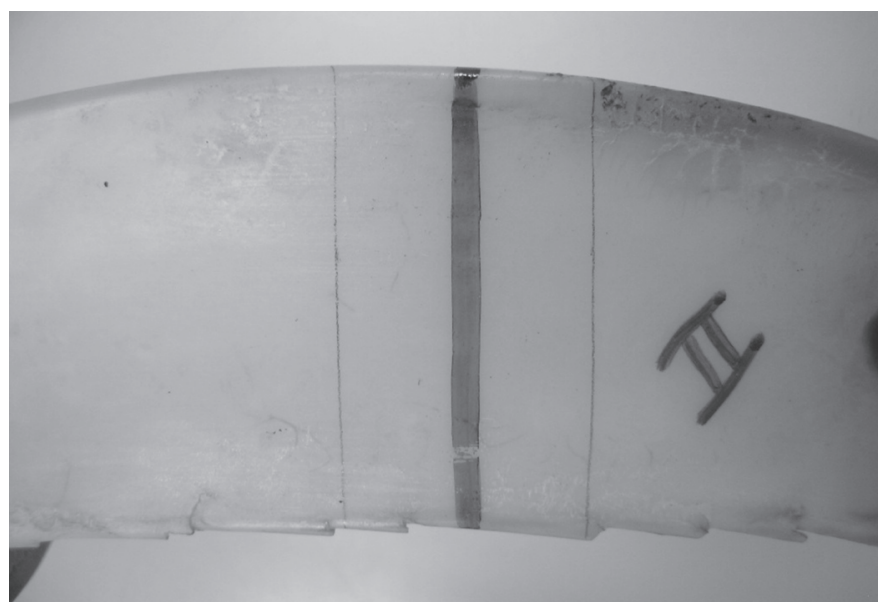

Fig.4. Representação do local de indução de fratura (linha azul) e área de preenchimento com resina acrílica (linhas cinzas).

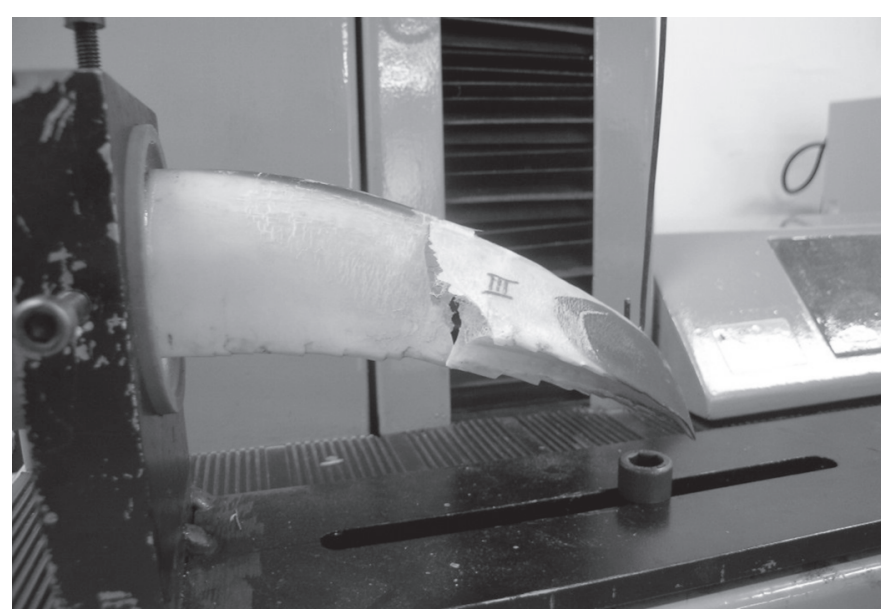

Fig.5. Fratura do bico no 1 em sua porção central, quando submetido à tração de $270,4 \mathrm{~N}$, com deslocamento de $22,59 \mathrm{~mm}$.
DL500MF. Programou-se a máquina para deslocamento do cabeçote com velocidade de $5 \mathrm{~mm} / \mathrm{min}$, até ruptura da amostra. Os dados obtidos eram convertidos, na forma de gráfico (Força versus Deslocamento) a um computador conectado ao dinamômetro (Fig.3).

Para a fixação dos bicos fraturados ( $n^{\text {os }} 2$ e 3) foram utilizadas as medidas preconizadas, pelo fabricante, de polímero e monômero da resina; e a área compreendeu uma faixa que se estendeu ao longo da linha de fratura $\mathrm{com} 2,0 \mathrm{~cm}$ de largura (1,0 cm para cada lado da fratura) (Fig.4). Para os demais ensaios realizados (bicos $n^{\circ} 4$ e 5), preencheu-se toda a superfície da rinoteca, inclusive palato.

A análise estatística dos dados obtidos foi realizada por meio do Teste Exato de Fisher.

\section{RESULTADOS E DISCUSSÃO}

O bico $\mathrm{n}^{\circ}$ 1, que estava íntegro (sem fratura induzida), fraturou em sua porção central (próximo à mediatriz do eixo rostro-caudal), quando submetido a uma tração de 270,4 N, com deslocamento de 22,59mm (Fig.5). A localização desta fratura serviu como orientação para a indução, através de uma serra de fita, das fraturas nos bicos que seriam reparados com resina (Fig.6).

O segundo bico ensaiado ( $n-2)$ recebeu a resina nas duas laterais e apresentou resistência até 69,75 N em 10,35mm (Fig.8). O bico nํㅜ, de forma a melhorar a aderência da resina, foi submetido a condicionamento ácido (ácido fosfórico 37\%) de 60 segundos antes da fixação da resina e resistiu a uma força de 63,29 $\mathrm{N}$ em 6,73mm de deslocamento (Fig.9).

Aquele bico não submetido ao condicionamento ácido ( $\mathrm{n}$ 으) resistiu até $134,4 \mathrm{~N}$ em 17,18 mm de deslocamento

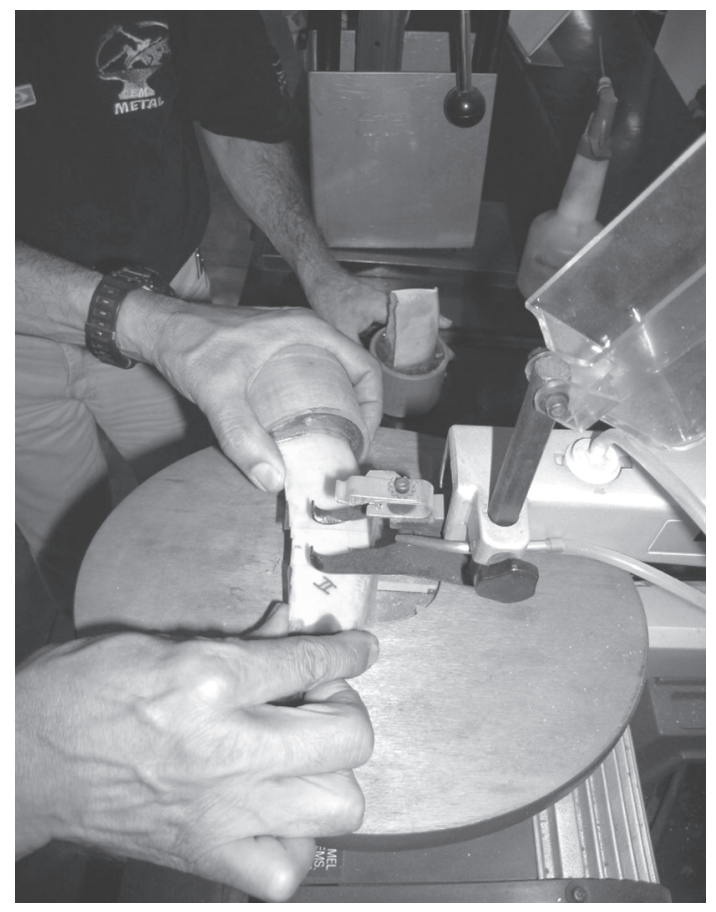

Fig.6. Indução de fratura completa na região central do bico com auxílio de serra de fita. 

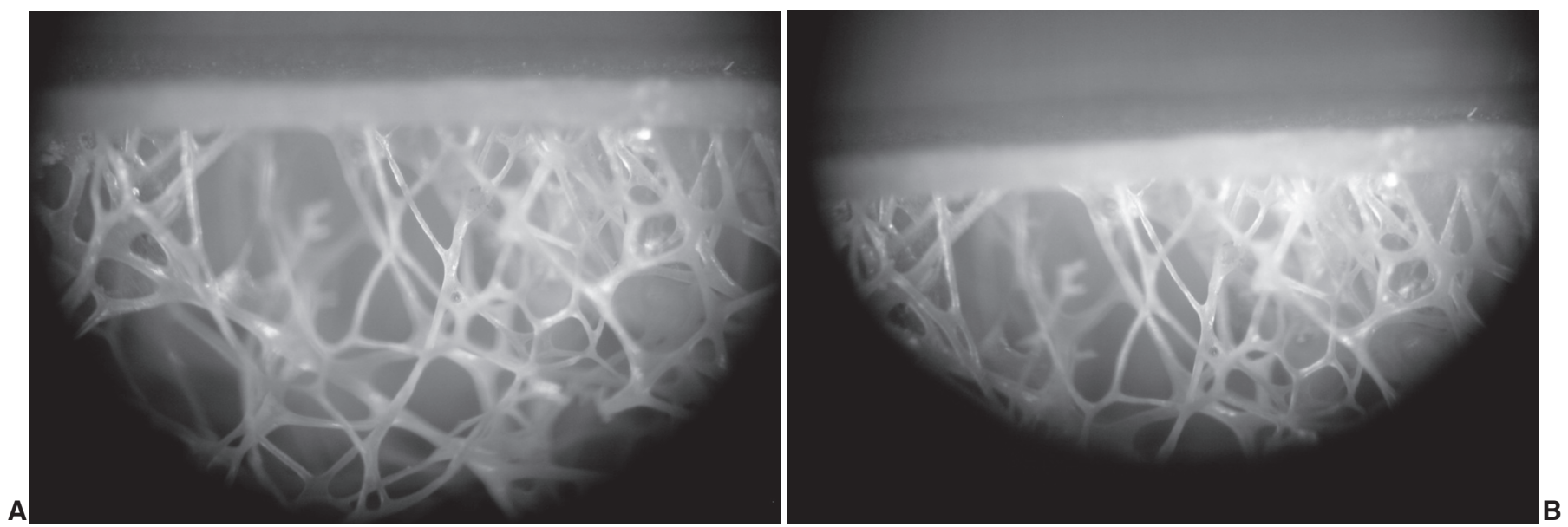

Fig.7. A. Superfície do bico antes da realização dos ensaios (sem resina). B Após a realização dos ensaios. Note que não há resquício do produto, demonstrando não haver aderência da mesma no estrato córneo queratinizado do bico.

e, aquele submetido ao ataque ácido ( $\mathrm{n}^{\circ}$ 5), resistiu até 101,5 N em 9,79mm de deslocamento (Fig.10 e 11).

Neste trabalho não foi observada correlação estatística e, conseqüentemente, diferença entre os procedimentos com utilização prévia de ataque ácido e aqueles sem a utilização do mesmo. Além disso, notou-se que o problema da reparação dos bicos parece estar relacionado à aderência da resina à queratina e não à resistência da mesma (Fig.7). Ainda, a fixação ao palato proporciona maior resistência do que quando se utiliza somente as faces laterais da rinoteca.

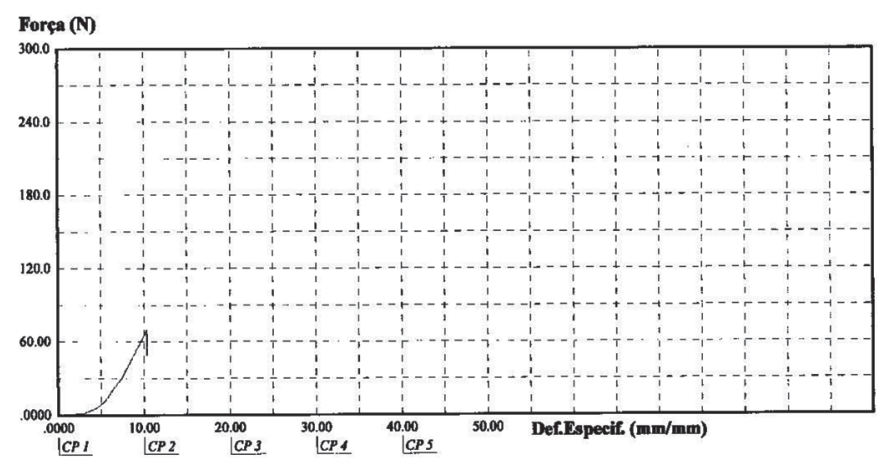

Fig.8. Representação gráfica da Força $(\mathrm{N})$ em função do Deslocamento $(\mathrm{mm})$ durante ensaio realizado com o bico $\mathrm{n}^{\circ} 2$.

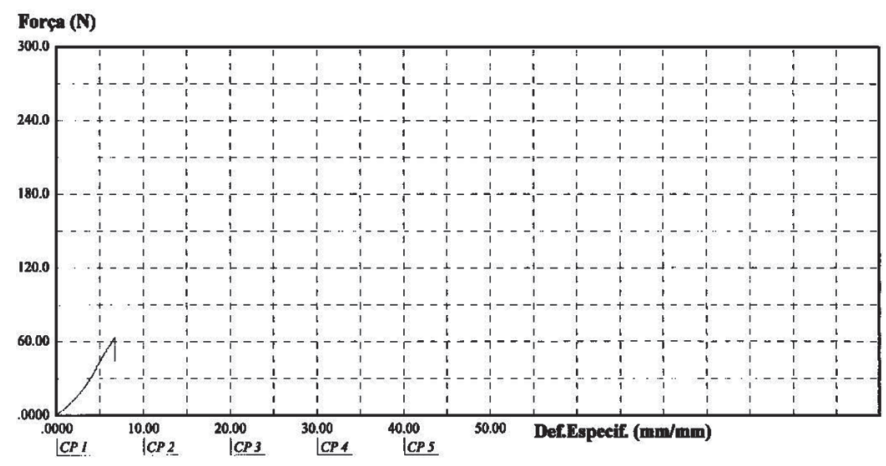

Fig.9. Representação gráfica da Força $(\mathrm{N})$ em função do Deslocamento $(\mathrm{mm})$ durante ensaio realizado com o bico $\mathrm{n}^{\circ} 3$.

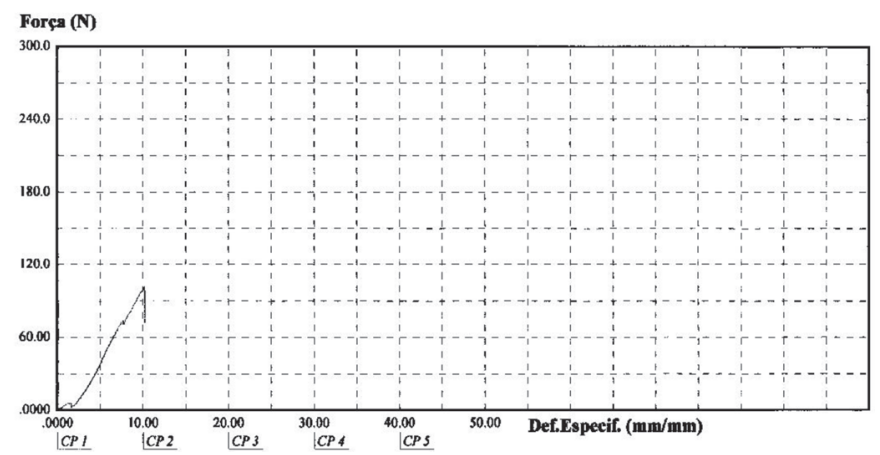

Fig.10. Representação gráfica da Força $(\mathrm{N})$ em função do Deslocamento $(\mathrm{mm})$ durante ensaio realizado com o bico $\mathrm{n}^{\circ} 4$.

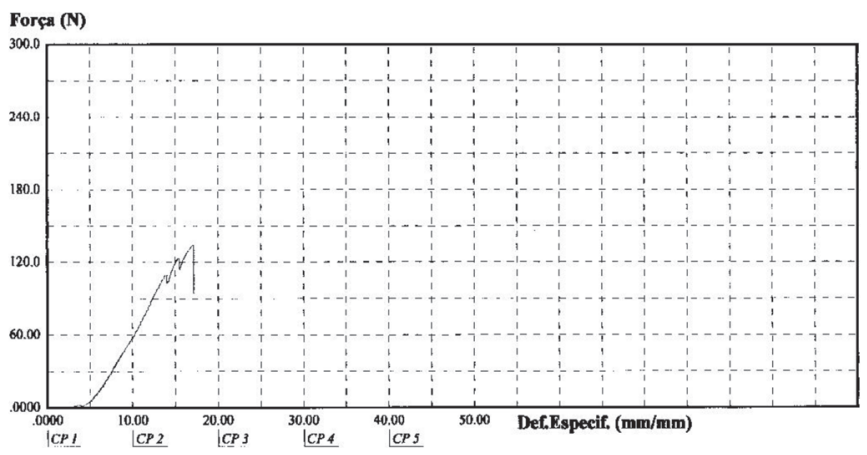

Fig.11. Representação gráfica da Força $(\mathrm{N})$ em função do Deslocamento $(\mathrm{mm})$ durante ensaio realizado com o bico $\mathrm{n}^{\circ} 5$.

A alta resistência à força oclusal de tração apresentada pelo bico controle ( $n^{-} 1$ ), com valor de $270,4 \mathrm{~N}$, representa grande desafio de reprodução durante a confecção de próteses. Os materiais sintéticos biocompatíveis disponíveis no mercado não são capazes de reproduzir tal resistência e, quando capazes de atingi-la, representam sobrepeso significativo à rinoteca.

Como representado nas Figuras 8 e 9, próteses recobrindo a superfície lateral da rinoteca proporcionam resistência aquém do necessário (cerca de $1 / 4$ dos valores obtidos com o bico controle) para as funções vitais do 
bico e, quando utilizadas em modelos in vivo, provavelmente comprometeriam sua sobrevida.

A utilização de resina acrílica sobre a superfície palatina da rinoteca (bicos nos 4 e 5), durante a fixação das próteses, proporcionou substancial resistência quando comparadas as demais, porém seus valores ainda ficam aquém do estabelecido com o bico controle (valores menores que $135 \mathrm{~N}$ ). Todavia, a fixação de resina acrílica na superfície palatina de modelos in vivo; trariam, provavelmente, prejuízo às funções de preensão e deglutição do alimento, bem como prováveis lacerações de língua.

\section{CONCLUSÕES}

O presente estudo, por meio de comparações entre as propriedades mecânicas e estruturais do bico de tucano, pôde evidenciar as seguintes conclusões:

A rinoteca íntegra de tucanos (Ramphastos toco) é capaz de resistir à força oclusal de tração de $270,4 \mathrm{~N}$;

Próteses de rinoteca fixadas exclusivamente com resina acrílica resistem à força oclusal de tração menor que $70,0 \mathrm{~N}$;

O condicionamento ácido (ácido fosfórico 37\%) prévio não proporciona melhora da aderência da resina à rinoteca;

Quando recoberta a superfície palatina durante a fixação da prótese, esta atinge valores de força oclusal de tração superiores àqueles observados quando somente a superfície lateral é recoberta, porém tais valores não atingem mais do que $134,4 \mathrm{~N}$;

Outras técnicas cirúrgicas de fixação (cerclagem e pinos, por exemplo) devem ser associadas à utilização de resina acrílica na fixação de próteses de rinoteca em tucanos (Ramphastos toco).

\section{REFERÊNCIAS}

Cubas S.Z2003. Order piciformes (toucans, woodpeckers): Beak repair, p.188-189. In: Fowler M.E. \& Cubas Z.S. (ed.), Biology, Medicine, and Surgery of South American Wild Animals. Iowa State University Press, lowa,

Fecchio R.S., Gomes M.S., Kolososki J., Petri B.S. \& Gioso M.A. 2005. Estudo da aderência da resina acrílica auto-polimerizável (Polimetilmetacrilato) em fraturas de rinoteca de tucanos (Ramphastos toco). Anais IX Congresso e XIV Encontro da Associação Brasileira de Veterinários de Animais Selvagens, São José do Rio Preto, SP, p.57.

Ford E. 1998. Falconry: Art and practice, p.28-31. Blandford, London.

Getty, R. 1989. Anatomia dos Animais Domésticos. Vol.2. $5^{\text {a }}$ ed. Guanabara Koogan, Rio de Janeiro.

Gioso M.A., Correa H.L., Venturini M.A.F.A. \& Rodrigues Filho L.E. 1995. Study of enamel micromorfologia and resistance to separation of composite restorations from teeth of dogs. Annals $4^{\text {th }}$ World Veterinary Dental Congress, Vancouver, Canada, p.94.

Meyers M.A., Lin A.Y.M., Seki Y., Chen P., Kad B.K. \& Bodde S. 2006. Structural biological composites: An overview. Journal of the Minerals, Metals and Materials Society 58(7):35-41.

Ritchie B.W., Harrison G.J. \& Harisson L.R. 1994. Avian Medicine: Principles and application. Wingers Publishing, Florida.

Rossi Jr J.L., Fecchio R.S., Guimarães M.B. \& Gioso M.A. 2005. Correção de fratura em gnatoteca de calopsita. Anais III Simpósio Brasileiro sobre Animais Silvestres e Selvagens, Universidade Federal de Viçosa, Viçosa. Impressão em mídia eletrônica (CD).

Rossi J.R., Baraldi-Artoni S.M., Oliveira D., Cruz C., Franzo V.S. \& Sagula A. 2005. Morphology of beak and tongue of partridge Rhynchotus rufescens. Ciência Rural 35:1098-1102.

Rupley A.E. 1999. Manual de Clínica Aviária. Roca, São Paulo. 